\title{
DIAGNOSTIC OF THE ATHLETE'S HEART AND FACTORS AFFECTING ITS DEVELOPING
}

D0I: 10.36740/WLek202105121

\author{
Serhiy V. Popov, Oleksandr I. Smiyan, Andrii M. Loboda, Viktoriia 0. Petrashenko, Olena K. Redko, Iryna I. Shkolna, \\ Alla V. Yurchenko \\ SUMY STATE UNIVERSITY, SUMY, UKRAINE
}

\begin{abstract}
The aim: Studying the features of the structure and function of the heart in athletes and identifying the factors that influence the development of these changes. Materials and methods: The study included 54 athletes, 29 men and 25 women. The ultrasound study was performed according to standard methods with determining the size of the main structures of the heart, indicators normalized to body surface area, height.

Results: The heart of dilatation and hypertrophy of the left ventricular myocardium were found in $25.93 \%$ of the athletes. When comparing the diameter of the left ventricle of individual athletes with the average values of the norm, their excess was found in $94.44 \%$ of athletes. The $0 \mathrm{dds}$ ratio (OR) of the relationship between left ventricle diameter (LVd) and time of the exercise less than $10 y$ was 16.13 , time of the exercise less than $5 y-0.17(p<0.05)$. OR of increase LVd to age less than 20 years was 3.56 units ( $p<0.05$ ). The ejection fraction was above the normative mean in $75.93 \%$, as well as the ratio of the periods of filling of the ventricles.

Conclusions: The most common sign of an athlete's heart development was left ventricular dilatation, which occurred at a rate of 25 percent. Age less than 20 years and the duration of sports activities from 5 to 10 years is associated with a higher frequency of the athlete's heart.
\end{abstract}

KEY WORDS: Athlete heart, physical exercises, left ventricle, function

Wiad Lek. 2021;74(5):1158-1163

\section{INTRODUCTION}

The study of the peculiarities of the state of the cardiovascular system in athletes is one of the important directions in the prevention of sudden death syndrome. The European Society of Cardiology (ESC) definition for sudden death (SD) is a nontraumatic, unexpected fatal event occurring within $1 \mathrm{~h}$ of the onset of symptoms in apparently healthy control [1]. Although the total number of athletes who died as a result of sudden death syndrome is small, it is growing $[2,3]$. On the one hand, athletes are one of the healthiest members of society with a high level of physical development. On the other hand, among people intensively involved in sports, the risk of sudden death is 2 times higher than in the general population. The most common causes of sudden death syndrome in athletes are hypertrophic cardiomyopathy and abnormal discharge of coronary arteries, less often - aortic dilatation, mitral valve prolapse, myocarditis $[3,4]$.

At the same time, there are a number of features in the structure of the heart and its function, which reflect the development of the so-called athlete's heart $[2,3,5,6,7]$. They require differential diagnosis with changes due to cardiac pathology $[1,2]$. For early diagnosis of the athlete's heart, differential diagnosis with anomalies and diseases of the cardiovascular system is recommended to study family history, life history, examination, which includes echocardiography.

\section{THE AIM}

The aim of the study was to study the characteristics of the structure and function of the heart in athletes, to identify the factors that influence the development of these changes.

\section{MATERIALS AND METHODS}

The study included 54 athletes, 29 men and 25 women, with an average age of $22.2 \pm 3.31$ years. The average time spent doing sports was $10.08 \pm 3.74$ years. The classification of Mitchell et al was used to assess the sport depending on the Isometric (Static) or Isotonic (dynamic) component [5, 8 ]. The number of athletes whose dynamic loads predominated was $48(88.89 \%)$, with a predominance of the static component - $6(11.11 \%)$.

Transthoracic echocardiography was performed to obtain images for analysis. The participants maintained in the supine position and left lateral decubitus position when scanning under peaceful breath. Ultrasonic measurements were processed in line with the recommendation of the American Society of Echocardiography and European Association of Cardiovascular Imaging [9]. Right ventricular mid-cavity diameter (RV, mm), Aorta annulus diameter (Ao, mm), Left atrium diameter (LA, mm), Left ventricular end-diastolic diameter ( $\mathrm{LVd}, \mathrm{mm})$, diastolic interventricular septal thickness (IVS, mm), Left ventricular diastolic posterior wall thickness (pwLV) were obtained 
Table I. Anamnestic data of the examined athletes

\begin{tabular}{cccc}
\hline Variable & Mean \pm SD & Variable & Mean \pm SD \\
\hline Male $(\mathrm{n} / \%)$ & $29 / 53,7$ & BMI $\left(\mathrm{kg} / \mathrm{m}^{2}\right)$ & $21,48 \pm 2,09$ \\
\hline Female $(\mathrm{n} / \%)$ & $25 / 46,3$ & Time of the Exercise $(\mathrm{y})$ & $10,08 \pm 3,74$ \\
\hline Age $(\mathrm{y})$ & $22,2 \pm 3,31$ & Time of Daily Mixed Exercise $(\mathrm{hrs})$ & $3,64 \pm 1,15$ \\
\hline Height $(\mathrm{cm})$ & $179,47 \pm 9,65$ & Time of Weekly Mixed Exercise $(\mathrm{hrs})$ & $17,81 \pm 5,46$ \\
\hline Weight $(\mathrm{kg})$ & $69,38 \pm 10,61$ & Dynamic prevalence (Isotonic, Isometric) type of the Exercise $(\mathrm{n} / \%)$ & $48 / 88,89$ \\
\hline BSA $\left(\mathrm{m}^{2}\right)$ & $1,89 \pm 0,21$ & Static prevalence (Isometric) type of the Exercise $(\mathrm{n} / \%)$ & $6 / 11,11$ \\
\hline
\end{tabular}

in the parasternal long-axis section of left ventricle. Left atrium diameter (LA) was normalized to body surface area $\left(\mathrm{LA} / \mathrm{BSA}, \mathrm{g} / \mathrm{m}^{2}\right)$, to height $(\mathrm{LAm} / \mathrm{h}, \mathrm{g} / \mathrm{m})$. Left ventricular mass $(\mathrm{LVm})$ was obtained by the standard cube formula and normalized to body surface area $\left(\mathrm{LVm} / \mathrm{BSA}, \mathrm{g} / \mathrm{m}^{2}\right)$, to height $(\mathrm{LVm} / \mathrm{h}, \mathrm{g} / \mathrm{m})$, to height in $2.7(\mathrm{LVm} / \mathrm{h} 2,7, \mathrm{~g} / \mathrm{m})$ The LV ejection fraction (EF) was calculated by standard formula. By Doppler echography the measurements of mitral and tricuspid inflow include the peak early filling (E-wave) and late diastolic filling (A-wave) velocities, the $\mathrm{E} / \mathrm{A}$ ratio (MV E/A and TV E/A), deceleration time (DTE) of early filling velocity (MV DTE and TV DTE) were obtained. To assess the frequency of increase in the obtained indicators relative to average values, threshold values of the norm, the recommended data were used $[10,11,12]$.

All statistical data were processed using a standard statistical formula. Continuous variables were confirmed for normal distribution by the Kolmogorov-Smirnov test and expressed as mean values \pm standard deviation $(\mathrm{M} \pm \mathrm{SD})$. Differences between the two groups in continuous variables were analyzed using an independent t-test for normal distribution. The odds ratio (OR) was obtained. For statistical significance calculating the criteria $\chi 2$, Fisher $(F)$, Student test $(\mathrm{t})$ were used. P-value $<0.05$ was considered statistically significant.

All research methods and experiments have been examined and approved by the appropriate ethics committee and have therefore been performed in accordance with the ethical standards laid down in the Declaration of Helsinki.

\section{RESULTS}

The average age of the athletes was $22.2 \pm 3.31$ years, body weight $69.38 \pm 10.61 \mathrm{~kg}$, BMI $21.48 \pm 2.09$, which was within the normal range (Table I.). The duration of sports activities was $10.08 \pm 3.74$ years, while the duration of activities per day was $3.64 \pm 1.15$ hours, and per week $-17.81 \pm 5.46$, which is considered an indicator of professional sports [9]. Most of the athletes were involved in a sport with a predominant dynamic component $-88.89 \%$ of athletes.

After performing the echocardiographic examination, a typical classic deviation for the athlete's heart was found - 14 $(25.93 \%)$ athletes had an increase in the diameter of the left ventricle at the end of systole above the standard value, 53 $\mathrm{mm}$ for women, $59 \mathrm{~mm}$ for men [10]. Another important abnormality is the increase in left ventricular myocardial thickness in response to static stress. However, the frequency of this deviation was very small - it was found in only $1 \mathrm{pa}-$ tient. To expand the possibilities of searching for deviations, we analyzed the number of studied indicators above the average for each of them, as well as exceeding the boundary values for some data. The guideline values were taken from the recommendations for performing echocardiographic studies [9]. The results are presented in Table II. Of the studied parameters, the average percentage of the standard value was exceeded for the left ventricular diastolic diameter (109.59 \pm 6.52$)$, the $L V d / B S A$ ratio $(119.15 \pm 12.58)$, the $L V d / h$ ratio (103.79 \pm 7.73 ). These changes were more common than an increase in LVd above the norm, respectively, in 51/94.44\% for LVd, 50/92.59\% for LVd/BSA and 35/64.82\% for $\mathrm{LVd} / \mathrm{h}$, with significant differences from the frequency of occurrence of indicators. below average. Evaluation of the frequency of the pwLV indicator above the average also showed its higher frequency than the increase above the boundary. The indicator was detected by $14 / 25.93 \%$ of athletes. However, the normalized indicators of heart mass to body surface area, height and height in the 2.7 degrees in most cases were below average. The indicator of the relative thickness of the myocardium looked similar, which was at the level of $90.68 \pm 10.56$ from the norm in the studied group of athletes

At the same time, the indicator characterizing myocardial contractility was more often higher than the average value in $43 / 75.93 \%$ of patients ( $p<0.001$ ). On the contrary, the heart rate was more often below the lower limit of the norm in $35 / 64.82$ athletes $(p<0.001)$. The diameter of the inferior vena cava was compared with the upper limit of the norm. An excess episode was found in $36 / 66.67 \%$ of athletes $(\mathrm{p}<0.001)$. We studied the indicators characterizing the diastolic function of the ventricles. They were also characterized by a high frequency of occurrence of values above the average for age and gender. Exceeding the average MV E / A was noted in 53/98.15\% of athletes, TV E/A - in $53 / 98.15 \%$. The excess of the average values for the parameters MV DTE and TV DTE was revealed somewhat less often - in $44 / 81.48 \%$ and $37 / 68.52 \%$, respectively.

To assess the degree of risk of influencing the factor on changes in the most significant indicators of the echocardiogram, the odds ratio parameters were calculated (Figure 1). An increase in the risk of left ventricular dilatation was found when playing sports with a predominance of the dynamic component, when playing sports for 5 to 10 years. There was an increased risk of an increase in the left ventricular diameter normalized to the body surface 
Table II. Echocardiographic data of the examined athletes

\begin{tabular}{|c|c|c|c|c|}
\hline Variable & Mean \pm SD & $\begin{array}{c}\text { Percent above normal mean }(\mathrm{m}) / \\
\text { border }(\mathrm{b}), \text { Mean } \pm S D\end{array}$ & $\begin{array}{c}\text { Number above mean/ } \\
\text { border, N/\% }\end{array}$ & $\mathbf{P}$ \\
\hline $\mathrm{RV}(\mathrm{mm})$ & $23,51 \pm 2,56$ & $87,07 \pm 9,48(\mathrm{~m})$ & $4 / 7,55$ & - \\
\hline Ao $(\mathrm{mm})$ & $29,85 \pm 2,71$ & $93,12 \pm 8,44(\mathrm{~m})$ & $6 / 11,32$ & - \\
\hline $\mathrm{LA}(\mathrm{mm})$ & $28,85 \pm 2,57$ & $85,27 \pm 7,23(\mathrm{~m})$ & $1 / 1,85$ & - \\
\hline $\mathrm{LA} / \mathrm{BSA}, \mathrm{cm} / \mathrm{m}^{2}$ & $1,55 \pm 0,19$ & $81,36 \pm 10,38(\mathrm{~m})$ & $2 / 3,7$ & - \\
\hline LVd (mm) & $53,09 \pm 4,44$ & $109,59 \pm 6,52(\mathrm{~m})$ & $51 / 94,44$ & $P<0,001$ \\
\hline $\mathrm{LVd} / \mathrm{BSA}, \mathrm{cm} / \mathrm{m}^{2}$ & $3,25 \pm 0,39$ & $119,15 \pm 12,58(\mathrm{~m})$ & $50 / 92,59$ & $P<0,001$ \\
\hline $\mathrm{LVd} / \mathrm{BSA}, \mathrm{cm} / \mathrm{m}^{2}$ & $3,25 \pm 0,39$ & $103,08 \pm 11,59(b)$ & $35 / 64,82$ & $P<0,001$ \\
\hline $\mathrm{LVd} / \mathrm{h}, \mathrm{cm} / \mathrm{m}$ & $2,96 \pm 0,22$ & $103,79 \pm 7,73(\mathrm{~m})$ & $35 / 64,82$ & $\mathrm{P}<0,01$ \\
\hline $\mathrm{LVd} / \mathrm{h}, \mathrm{cm} / \mathrm{m}$ & $2,96 \pm 0,22$ & $90,91 \pm 6,51(b)$ & $6 / 11,32$ & - \\
\hline IVS (mm) & $7,44 \pm 0,88$ & $95,69 \pm 9,69(\mathrm{~m})$ & $8 / 14,82$ & - \\
\hline pwLV (mm) & $7,69 \pm 0,95$ & $98,81 \pm 10,76(\mathrm{~m})$ & $14 / 25,93$ & - \\
\hline $\mathrm{EF}$ & $64,54 \pm 2,74$ & $121,23 \pm 11,47(\mathrm{~m})$ & $43 / 75,93$ & $P<0,001$ \\
\hline HR (bpm) & $57,04 \pm 9,18$ & $95,06 \pm 15,3$ (b) & $35 / 64,82$ & $P<0,001$ \\
\hline LVm/BSA $\left(\mathrm{g} / \mathrm{m}^{2}\right)$ & $61,62 \pm 12,29$ & $81,02 \pm 13,53(\mathrm{~m})$ & $5 / 9,26$ & - \\
\hline $\mathrm{LVm} / \mathrm{h}(\mathrm{g} / \mathrm{m})$ & $65,04 \pm 16,11$ & $80,85 \pm 15,26(\mathrm{~m})$ & $6 / 11,11$ & - \\
\hline $\operatorname{LVm} / \mathrm{h}^{2,7}(\mathrm{~g} / \mathrm{m})$ & $24,05 \pm 5,54$ & $73,62 \pm 15,71(\mathrm{~m})$ & $4 / 7,4$ & - \\
\hline MV E/A & $2,21 \pm 0,33$ & $138,26 \pm 20,75(\mathrm{~m})$ & $53 / 98,15$ & $P<0,001$ \\
\hline MV DTE (sec) & $198,18 \pm 33,99$ & $123,87 \pm 21,24(\mathrm{~m})$ & $44 / 81,48$ & $P<0,001$ \\
\hline TV E/A & $2,12 \pm 0,26$ & $151,29 \pm 18,46(\mathrm{~m})$ & $53 / 98,15$ & $\mathrm{P}<0,001$ \\
\hline TV DTE (sec) & $204,33 \pm 33,89$ & $113,52 \pm 18,23(\mathrm{~m})$ & $37 / 68,52$ & $P<0,001$ \\
\hline
\end{tabular}

depending on the female sex for the borderline and average values of the norm. The risk of increased thickness of the posterior wall of the left ventricular myocardium was increased in the male field of the athlete.

\section{DISCUSSION}

The most common change found in the study was signs of left ventricular dilatation in $14(25.93 \%)$ athletes. These changes are typical for athletes who perform loads with a predominantly dynamic component. They are associated with increased cardiac output and decreased peripheral vascular resistance, resulting in volume overload. In general, this can lead to an increase in the absolute size of all chambers of the heart, but, first of all, the left ones $[1,3,4,6,9]$.

The calculation of the odds ratio confirmed the influence of the dynamic type of load on the size of the heart chambers; the OR value showed an increase in the risk of left ventricular dilatation by 4.38 times $(p=0.046)$. Since left ventricular dilatation was found in only $25 \%$ of athletes, an attempt was made to assess the prevalence of left ventricular enlargement by determining the frequency with which the LVd value was higher than the reference mean (10). In 51 (94.44\%) athletes, such an increase was found, which was significantly higher than the number of athletes with LVd below average (Table II).

Thus, the increase in the left ventricle occurred in the absolute majority of athletes, but only $25.93 \%$ above the limit value of the norm. This led to an attempt to identify possible factors that might influence the development of left ventricular dilatation (Figure 1). The OR parameters showed that the risk of dilatation increased by 3.25 times with the time of sports less than 10 years, whereas with the time of sports less than 5 years, it decreased to 0.17 units. A similar picture was observed for $\mathrm{LVd}$ values above average. This could indicate that an increase in the left ventricular diameter above average values and its dilatation are more characteristic for the period of time spent in sports from 5 to 10 years. It is indicated that for older athletes, the indicators of the volume of the heart chambers and the thickness of the heart muscle may be less than in young athletes, while remaining, at the same time, higher than in people who are not involved in professional sports $[1,7,9]$. The results of the analysis of the relationship between the age of the athlete and the risk of developing left ventricular dilatation to a certain extent can confirm this, the risk of dilatation increased by 3.56 times at the age of less than 20 years. This can be explained both by age-related changes and, possibly, by the time of improvement of the adaptive responses of the cardiovascular system $[1,9]$.

The odds ratio indicated a slight increase in the risk of developing left ventricular dilatation in women. It was equal to 1.41 ( $p>0.05)$. It is indicated that women show the same adaptive response to increased loads, depending on its type, but the changes are more moderate (9). In our study, the OR indicator obtained reflected the gender difference in engaging in various sports, the static component prevailed in men (Figure 1). 


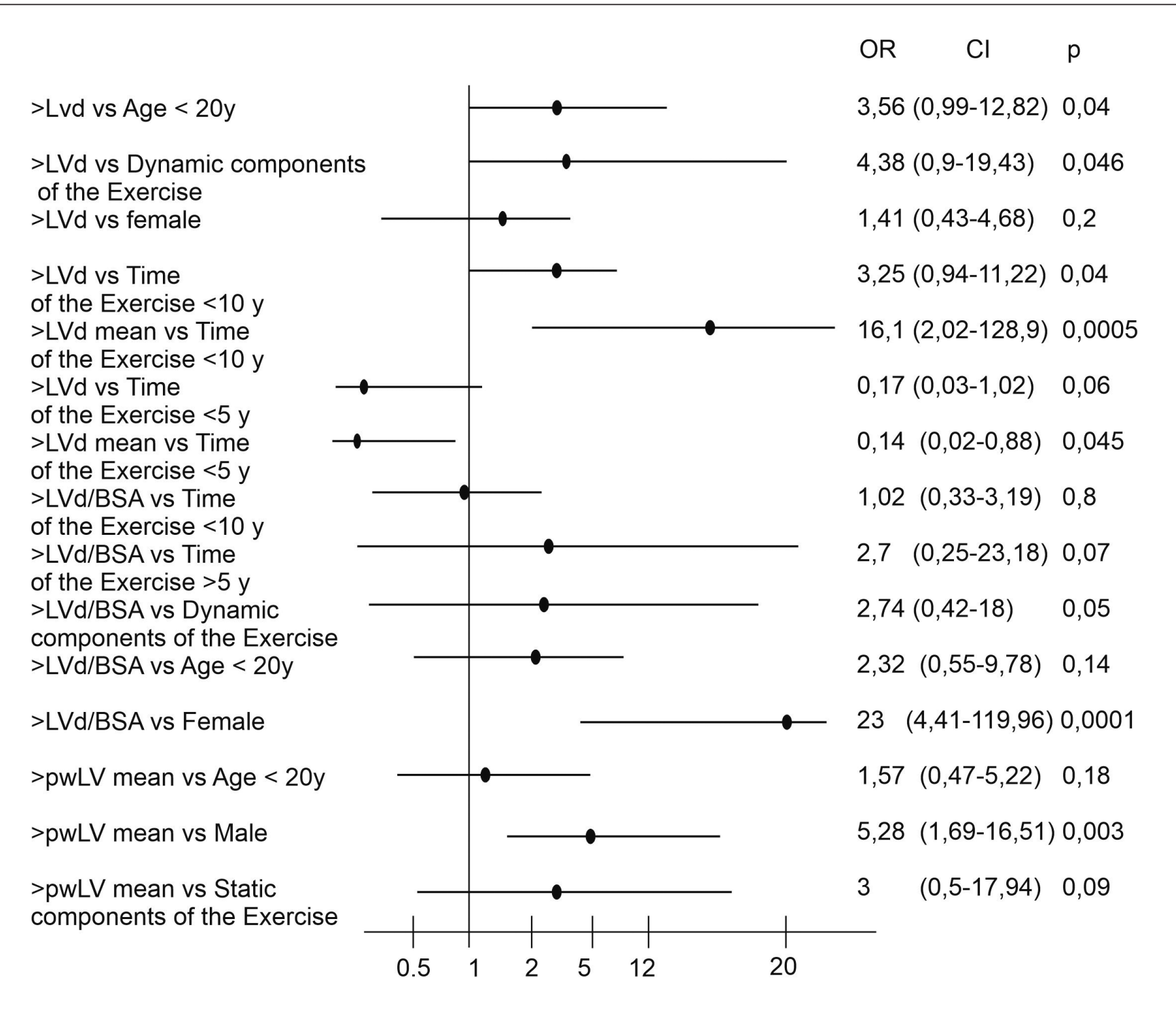

Fig. 1. Dependence of changes in echocardiography parameters and anamnestic data.

Normalization of indicators to BSA and Height values can objectify them $(9 ; 13)$. The LVd/BSA indicator $(94.44 \%)$ for exceeding the average values was at the same sensitivity level as LVd (92.59), while LVd/h (64.82) turned out to be less sensitive. Determination of indicators above the norm for LVd/BSA showed a higher detectability of changes. However, this indicator turned out to be gender-dependent with female, OR was $23(\mathrm{p}<0.05)$.

Another typical change in the heart of an athlete is a thickening of the left ventricular myocardium. It is a manifestation of an adaptive response to a static isometric load and is characterized by a slight increase in cardiac output and a transient increase in peripheral resistance, characterizing pressure overload $[1,3,9]$. In our study, there were only 6 athletes with a predominantly static load. And only one athlete showed an increase in myocardial thickness above the norm. An assessment was made of the frequency of detection of pwLV values above the average value of the norm, the dependence of this indicator on the data under study. In
$14(25.93 \%)$ athletes, these changes were found. The odds ratio showed an increase in the risk of an increase in pwLV when playing sports with a static component 3 times higher than the average value $(p>0.05)$. As with the LVd parameter, the chances of an increase in this indicator were higher for athletes less than 20 years old. Evaluation of the odds ratio parameter showed an increase in the risk of thickening of the posterior wall of the left ventricular myocardium in the time interval from 5 to 10 years of sports $(p<0.05)$. For the pwLV mean parameter, gender dependence was determined, the risk of its increase increased by 5.28 times $(p=0.003)$ in men. This can be explained by the fact that sports with a static component are more often observed in men $[13,14]$.

The group of indicators reflecting the heart mass and normalized to the body surface, height, height raised to the power of 2.7, turned out to be less sensitive compared to the thickness of the posterior wall of the left ventricular myocardium. The frequency of detectability of an increase in these indicators above the average was 2-3 times lower. As for the 
LVd/BSA indicator, this can be explained by the change in the actual normalizing factors in athletes over time.

Indicators reflecting the size of the left atrium, aorta, right ventricle changed to a lesser extent. the frequency of exceeding the average was low. This can be explained by the peculiarities of the dimensions taken for analysis, in particular for the aorta the level of aorta annulus, for the right ventricle its average size. On the other hand, the linear size of the left atrium does not always reflect changes in the actual size of the left atrium. This also applies to LA normalized to body surface area. Changes in the diameter of the aorta are defined by some authors as minimal $[1,3]$.

The average value of the heart rate was below the standard value $-57.04 \pm 9.18$. A decrease in HR was found in $35 / 64.82 \%$ of athletes. This is a characteristic feature of athletes $[7,15]$.

Assessment of the systolic function of the left ventricle showed its values within the norm. However, when analyzing the frequency of exceeding the average value, it turned out to be high and was noted in $43 / 75.93 \%$ of athletes. Normal systolic function or its increases in general is characteristic of athletes and is determined by adaptive responses to exercise [7].

The ratios MVE/A, TV E/A, MV DTE and TV DTE allow us to assess the diastolic function of the heart. Based on the results obtained, the indicators were higher than normal in most athletes. A number of authors indicate that the diastolic function in athletes is normal or increased $[1,4,7,16]$.

\section{CONCLUSIONS}

The most common sign of an athlete's heart development was left ventricular dilatation, which occurred at a rate of 25 percent and was determined by Mixed load with a predominance of the dynamic component. In 95 percent of athletes, the left ventricle diameter exceeded the average values of the norm.

Age less than 20 years and the duration of sports activities from 5 to 10 years is associated with a higher frequency of detection of an increase in the left ventricular diameter and the development of a athlete's heart.

The systolic and diastolic heart functions in the examined athletes were at the supranormal level.

\section{REFERENCES}

1. Radmilovic J., D'Andrea A., D'Amato A. et al. Echocardiography in Athletes in Primary Prevention of Sudden Death. J Cardiovasc Echography. 2019;29(4):139. doi:10.4103/jeecho.jcecho_26_19.

2. La Gerche A., Baggish A.L., Knuuti J. et al. Cardiac Imaging and Stress Testing Asymptomatic Athletes to Identify Those at Risk of Sudden Cardiac Death. JACC: Cardiovascular Imaging. 2013;6(9):993-1007. doi:10.1016/j.jcmg.2013.06.003.

3. Grazioli G., Sanz M., Montserrat S., Vidal B., Sitges M. Echocardiography in the evaluation of athletes. F1000Res. 2015;4:151. doi:10.12688/ f1000research.6595.1.

4. Prior D. Differentiating Athlete's Heart from Cardiomyopathies The Right Side. Heart, Lung and Circulation. 2018;27(9):1063-71. doi:10.1016/j.hlc.2018.04.300.
5. Pelliccia A. Recommendations for competitivesports participation in athletes with cardiovascular disease: A consensus document from the Study Group of Sports Cardiology of the Working Group of Cardiac Rehabilitation and Exercise Physiology and the Working Group of Myocardial and Pericardial Diseases of the European Society of Cardiology. European Heart Journal. 2005;26(14):1422-45. doi:10.1093/eurheartj/ehi325.

6. Rosen Y., Chera H., Abdulrazzaq M. et al. The Role of Echocardiography in Evaluation of Athletic Heart: A Scoping Study. Int I Clin Res Trials. 2020; 5(2). doi:10.15344/2456-8007/2020/153.

7. Li P., Zhang Y., Li L. et al. Assessment of left ventricular systolic function by non-invasive pressure-strain loop area in young male strength athletes. Cardiovasc Ultrasound. 2020;18(1):45. doi:10.1186/s12947020-00227-w.

8. Mitchell J.H., Haskell W., Snell P., Van Camp S.P. Task Force 8: Classification of sports. Journal of the American College of Cardiology. 2005;45(8):1364-7. doi:10.1016/j.jacc.2005.02.015.

9. Pelliccia A., Caselli S., Sharma S. et al. European Association of Preventive Cardiology (EAPC) and European Association of Cardiovascular Imaging (EACVI) joint position statement: recommendations for the indication and interpretation of cardiovascular imaging in the evaluation of the athlete's heart. European Heart Journal. 2018;39(21):1949-69. doi:10.1093/eurheartj/ehx532.

10. Lang R.M., Badano L.P., Mor-Avi V. et al. Recommendations for Cardiac Chamber Quantification by Echocardiography in Adults: An Update from the American Society of Echocardiography and the European Association of Cardiovascular Imaging. Eur Heart J Cardiovasc Imaging. 2015;16(3):233-271. doi:10.1093/ehji/jev014.

11. Nagueh S.F., Smiseth O.A., Appleton C.P. et al. Recommendations for the Evaluation of Left Ventricular Diastolic Function by Echocardiography: An Update from the American Society of Echocardiography and the European Association of Cardiovascular Imaging. Journal of the American Society of Echocardiography. 2016;29(4):277-314. doi:10.1016/j. echo.2016.01.011.

12. Ciozda W., Kedan I., Kehl D.W. et al. The efficacy of sonographic measurement of inferior vena cava diameter as an estimate of central venous pressure. Cardiovasc Ultrasound. 2015;14(1):33. doi:10.1186/ s12947-016-0076-1.

13. Utomi V., Oxborough D., Whyte G.P. et al. Systematic review and metaanalysis of training mode, imaging modality and body size influences on the morphology and function of the male athlete's heart. Heart. 2013;99(23):1727-33. doi:10.1136/heartjnl-2012-303465.

14. Pelà G., Crocamo A., Li Calzi M. et al. Sex-related differences in left ventricular structure in early adolescent non-professional athletes. Eur JPrev Cardiolog. 2016;23(7):777-84. doi:10.1177/2047487315608826.

15. Czimbalmos C., Csecsl., Dohy Z. et al. Cardiac magnetic resonance based deformation imaging: role of feature tracking in athletes with suspected arrhythmogenic right ventricular cardiomyopathy. Int I Cardiovasc Imaging. 2019;35(3):529-38. doi:10.1007/s10554-018-1478-y.

16. D'Andrea A., Bossone E., Radmilovic J. et al. The role of new echocardiographic techniques in athlete's heart. F1000Res. 2015;4:289. doi:10.12688/f1000research.6745.1.

Article was performed in framework of research "Infectious and somatic diseases in children: peculiarities of the current course and ways to improve their treatment», № 0120U102150, Academic adviser Smiyan O.I., MD, DM, Professor, terms of research 05.2020-05.2025. 
ORCID and contributionship:

Serhiy V. Popov: 0000-0002-17891474 A, B, C, D

Oleksandr I. Smiyan: 0000-0001-8225-0975 ${ }^{\text {A }}$

Andrii M. Loboda: 0000-0002-5400-773X ${ }^{A}$

Viktoriia O. Petrashenko: 0000-0002-4648-8916 ${ }^{D}$

Olena K. Redko: 0000-0001-5501-829X ${ }^{E}$

Iryna I. Shkolna: 0000-0001-6756-0158 ${ }^{D, F}$

Alla V. Yurchenko: 0000-0002-9707-8829 ${ }^{D}$

\section{Conflict of interest:}

The Authors declare no conflict of interest.

\section{CORRESPONDING AUTHOR}

Serhiy V. Popov

Sumy State University

2 Rymskogo-Korsakova st., 40007 Sumy, Ukraine

tel: +380668129367

e-mail:s.popov@med.sumdu.edu.ua

Received: 18.12 .2020

Accepted: 30.03 .2021

A - Work concept and design, B - Data collection and analysis, C - Responsibility for statistical analysis,

D-Writing the article, $\mathbf{E}$-Critical review, $\mathbf{F}$ - Final approval of the article 